\title{
THE EFFECTS OF MINIMUM WAGES ON TEENAGE EMPLOYMENT AND ENROLLMENT: EVIDENCE FROM MATCHED CPS SURVEYS
}

David Neumark

William Wascher

Working Paper No. 5092

\section{NATIONAL BUREAU OF ECONOMIC RESEARCH 1050 Massachusetts Avenue \\ Cambridge, MA 02138 \\ April 1995}

We thank Charles Brown, Bruce Fallick, Harry Holzer, Jim Spletzer, Jeff Wooldridge, and seminar participants at Michigan State University, Indiana University and IUPUI for helpful comments. This paper is part of NBER's research program in Labor Studies. Any opinions expressed are those of the authors and not those of the Federal Reserve Board, its staff, or the National Bureau of Economic Research.

(C) 1995 by David Neumark and William Wascher. All rights reserved. Short sections of text, not to exceed two paragraphs, may be quoted without explicit permission provided that full credit, including () notice, is given to the source. 


\title{
THE EFFECTS OF MINIMUM WAGES ON TEENAGE EMPLOYMENT AND ENROLLMENT: EVIDENCE FROM MATCHED CPS SURVEYS
}

\begin{abstract}
The recent debate over minimum wages raises two questions. First, should policy makers no longer believe that minimum wages entail negative consequences for teenagers? Second, should economists discard the competitive labor market model? Our evidence for teenagers, using matched CPS surveys, suggests that the answer to both of these questions is no. We find that although increases in minimum wages have small net effects on overall teen employment rates, such increases raise the probability that more-skilled teenagers leave school and displace lower-skilled workers from their jobs. These findings are consistent with the predictions of a competitive labor market model that recognizes skill differences among workers. In addition, we find that the displaced lower-skilled workers are more likely to end up non-enrolled and nonemployed. Thus, despite the small net disemployment effects for teenagers as a group, there are significant enrollment and employment shifts associated with minimum wage changes that should be of concern to policy makers.
\end{abstract}

David Neumark Department of Economics Michigan State University East Lansing, MI 48824 and NBER
William Wascher

Board of Governors of the

Federal Reserve System 20th and Constitution, NW Washington, DC 20551 


\section{$\underline{\text { I. Introduction }}$}

The recent debate about the impact of minimum wages on the labor market has focused on the net employment effects of raising the minimum wage. Some studies have challenged the conventional view that minimum wages reduce employment among youths, while other studies have confirmed the conventional wisdom. ${ }^{1}$ Although methodologies used in the recent studies differ in important ways from earlier research, in many respects the debate has turned on the same issues that permeated the discussion in the early 1980s when the Minimum Wage Study Commission was asked to review the evidence on minimum wages.

The attention given to aggregate net employment effects is perhaps a natural one, given the political attractiveness of simple or straightforward answers to economic questions. However, this narrow focus is also subject to the criticism--originally made by Abowd and Killingsworth (1981)-that estimates of minimum wage effects computed for aggregate demographic groups, such as all teenagers, are inadequate for understanding the workings of low-wage labor markets.

This implicit aggregation may have very serious consequences, because it ... may mask important effects within such aggregates. For example, a rise in the minimum wage may have sharp negative effects on some teenage subgroups; sharp positive effects on other teenage subgroups; and, overall, a relatively small net effect ... Under such circumstances, information concerning net effects only does not tell the whole story about the consequences of an increase in the minimum wage. (p. 144)

Abowd and Killingsworth describe the strategy of aggregation of persons with varying skill levels into a given demographic group as an act of "empirical desperation" attributable to the fact that

${ }^{1}$ Recent studies challenging the conventional wisdom include Card (1992a and 1992b), Katz and Krueger (1992), Card and Krueger (1994), Krueger (1994), Machin and Manning (1994), Spriggs (1992), and Wellington (1991). Recent studies tending to confirm the conventional wisdom include Baker, et al. (1994), Castillo-Freeman and Freeman (1992), Currie and Fallick (1993), Neumark and Wascher (1992 and 1994b), Williams (1993), and Kim and Taylor (1995). Of course there is a much larger, earlier body of literature using time-series data, and a smaller, earlier body of literature using cross-section or panel data. These are reviewed in Brown, et al. (1983). 
skill is not directly observed in the macro time-series data used in the studies that comprise most of the work of the Minimum Wage Study Commission (p. 145). ${ }^{2}$ However, the same aggregation is used in much of the recent research on minimum wages--our own included.

In previous research, we addressed some of these issues in the context of aggregate statelevel data for teenagers, finding in particular that although the net disemployment effect of minimum wages is relatively small, a higher minimum tends to decrease school enrollment and increase the proportion of teenagers neither enrolled nor employed (Neumark and Wascher, 1995). However, the aggregate data were not rich enough to distinguish among competing hypotheses about the relationship between minimum wages and school-to-work transitions. For example, one interpretation of our finding is that a higher minimum increases the relative demand for enrolled (higher-quality or more-skilled) teenagers, bidding up their market wages and inducing some of them to leave school for employment. Under this scenario, these higher-skilled teenagers then displace lower-skilled teenagers not in school and employed at or near the old minimum. However, an alternative interpretation--equally consistent with the results from the aggregate data-is that minimum wage increases reduce enrollments as teens leave school and queue for jobs at the higher minimum, without any displacement of teenagers already employed.

In this paper, we attempt to provide a fuller description of the effects of minimum wages on teenagers than is afforded by estimates of employment effects for teenagers as a whole, or by state-level data on employment and enrollment rates. In particular, we use individual-level panel data, from matched CPS's, on school and work transitions of teenagers, to extend the existing research in a number of directions. First, data on transitions among school and work activities allow us to test the alternative substitution and queuing interpretations of the school/work

${ }^{2}$ Abowd and Killingsworth do not introduce new data that breaks up the traditional demographic groups based on skill-related characteristics. 
transitions caused by minimum wages. Second, the individual-level data enable us to estimate minimum wage effects on school and work for various subgroups of teenagers distinguished by skill-related characteristics. Third, the longitudinal nature of the data enable us to examine the effects of binding minimum wages directly, by distinguishing between teenagers with wages originally above or below a new minimum wage.

Our results are consistent with the competitive model of low-wage labor markets and its implications for minimum wage effects, as long as we recognize that workers are heterogeneous in skills. An increase in the minimum wage reduces employment among less-skilled workers, with the strongest effects evident for workers at the old minimum wage. In addition, there is a sizable supply response among more-skilled teenagers, with a tendency for some to leave school for employment after an increase in the minimum. In short, the evidence suggests that minimum wage increases induce employers to substitute away from less-skilled teenagers and toward more-skilled teenagers drawn into the labor market. The end result is that fewer teenagers remain in school, while the lowest-skilled teenagers are displaced from their jobs.

\section{Previous Research}

Although most of the previous research on minimum wages has focused on relationships between overall teen or young adult employment rates and the minimum wage, there has been some attention paid to three points especially relevant to this paper. First, a few papers have considered empirical evidence on the possibility that minimum wage increases affect the wages other workers may earn. This is potentially important, because the substitution or displacement explanation of our findings may entail some bidding up of wages for above-minimum-wage 
workers. ${ }^{3}$ Second, a few papers have focused on minimum wage effects for those earning wages at or near the minimum. Third, some previous research has examined the effects of minimum wages on schooling.

\section{Spillover Effects}

Gramlich (1976) considered the possibility that minimum wage increases lead to wage increases for other, higher-paid workers "through a ... traditional demand-supply route following substitution by employers away from low-wage labor toward skilled labor" (p. 427). ${ }^{4}$ Gramlich provides some evidence that wages for higher-quality workers rise in response to minimum wage increases, showing that in aggregate Phillips curve estimates, overall hourly wages increase significantly in response to minimum wage increases, by a factor twice as large as would be expected based on the higher wage paid to minimum wage workers (pp. 427-9).

Grossman (1983) presents a model in which workers' productivity is positively related to their relative wage, leading employers to bump up the wages of higher-skilled workers in response to a minimum wage increase. Using Area Wage Surveys, she presents evidence on occupations for which all sampled wages exceeded the minimum wage in the state (the higher of the state or

${ }^{3}$ This is not required. Even teenagers who would have earned less than the new minimum prior to the wage increase (but more than the old minimum) may now be able to earn the new minimum, as the increase in demand for their labor may raise their equilibrium wage to the new minimum wage (or higher).

${ }^{4} \mathrm{~A}$ related possibility is suggested by Meyer and Wise (1983). They assume a labor market in which there are several types of labor which are only imperfect substitutes, so that the marginal product of each type depends on the level of employment of the other types. Suppose a minimum wage is imposed which is above the marginal products of some of these types ("low quality"). Then employment of these types is reduced, raising their marginal products to the minimum. In addition, the marginal productivity of "high quality" labor may rise as this occurs, leading to higher wages for these workers. Note, also, that this model potentially explains why minimum wages lead to spikes in the wage distribution. As Brown (1988) pointed out, such spikes would not be predicted if workers of different quality were perfectly substitutable, representing only different efficiency units of labor. 
federal level). Her findings indicate that for some of these occupations, especially white-collar jobs, wages respond to minimum wage increases. Grossman also attempts to sort out substitution from relative income effects, claiming that the former should occur with a lag, and the latter instantaneously. But this is not a sharp test, and the evidence is inconclusive.

Meyer and Wise (1983) also obtain results relevant to the hypothesis that wages for moreskilled workers respond to minimum wage changes, as a by-product of their analysis of the employment effects of minimum wages. They estimate a market wage function that is truncated at the minimum and corrected for changes in the wage distribution induced by minimum wage legislation. In pooled time-series, cross-section data they find year effects in this market wage distribution. In principle, these year effects could reflect spillovers from minimum wage increases. However, the year effects are not largest in the years in which the real minimum wage (defined relative to an adult area wage index) is highest, and therefore suggest that "other determinants of youth wage rates relative to adult rates, like the relative numbers of young and older persons" (p. 84), may be the cause.

\section{Effects on Low-Wage Workers}

There have also been some attempts to estimate minimum wage effects for those most likely to be affected by the minimum. For example, we have used a disequilibrium endogenous switching model of the labor market to estimate minimum wage effects at the state level for those states and years in which minimum wages are relatively more likely to be binding (Neumark and Wascher, 1994a). Our results indicate that the effects of binding minimum wages for workers aged 16-24 are significantly larger than the estimates obtained from single-equation methods that do not differentiate the effects of a minimum wage increase based on the level of the minimum wage relative to the equilibrium wage. 
Currie and Fallick (1993) take an approach paralleling the part of this paper that distinguishes between above- and below-minimum wage workers. Using the NLSY sample, they focus on the 1980 and 1981 increases in the federal minimum. They first define workers as bound by the minimum wage if their wage in a base year is less than the minimum wage in the following year, but no less than the minimum wage in the base year. They then define the "wage gap" as the difference between workers' base-year wages and the new minimum, setting it to zero for those not bound by the minimum. Using these definitions, they estimate OLS, random effects, and fixed effects estimates of linear probability models of employment in the year following the base year. They find that the wage gap is significantly negatively related to employment, and that, at the mean wage gap, being bound by the minimum wage reduces the probability of employment by $.03-.04 .^{5}$ Obviously, this approach to estimating minimum wage effects requires fewer structural assumptions than does our disequilibrium approach, which is the reason we are interested in pursuing it here. However, our work differs in two important ways. First, owing to the limited age cohorts and early starting year of the NLSY, Currie and Fallick were restricted to looking only at the effects of the 1980 and 1981 federal minimum wage increases on teen employment. In contrast, by using the matched CPS's, we can include state and federal minimum wage increases through 1992. Second, we look at effects on employment and enrollment, and on the transitions between these activities. This is of particular interest in light of our findings in state-level data that minimum wage increases appear to result in enrollment declines and increases in the proportion of teenagers both out of school and out of work.

The studies reviewed above estimate the effects of minimum wages on low-wage workers

\footnotetext{
${ }^{5}$ The random and fixed effects estimates use data on many years following the federal minimum wage increases to allow for heterogeneity in the propensity to be employed. Thus, the fixed effects estimates imply that the lower employment probabilities of those bound by the minimum wage are not attributable to lower employment propensities of low-wage workers.
} 
via refinements of regressions of employment rates on minimum wages. In contrast, Meyer and Wise (1983) estimate the disemployment effect by parameterizing the market wage distribution, taking account of the possibility that minimum wages may either bump up the market wage of those below the minimum or cause them to be non-employed. This procedure enables them to estimate the proportion that would be working in the absence of the minimum. Simulations based on their estimates imply that minimum wage effects on employment of teenagers are somewhat larger in absolute value than the -.1 to -.2 elasticities associated with time-series studies (see, e.g., Brown, 1988). The Meyer and Wise results emphasize, however, that disemployment effects among the lowest-wage workers may be quite severe.

\section{Schooling Effects}

A smaller body of research has addressed the relationship between minimum wages, school enrollment, and employment. In our previous work on this subject (Neumark and Wascher, 1995), state-level data indicate that minimum wages decrease enrollments of teenagers and increase the proportion of teenagers neither enrolled nor employed. One interpretation of this finding is that minimum wage increases boost the relative demand for enrolled teenagers, bidding up their wages and inducing some of them to leave school for employment; the result is that lower-wage teenagers not in school are displaced from their jobs. An alternative explanation is that minimum wages reduce enrollments by inducing teenagers to leave school to queue for jobs at the higher minimum. These explanations are observationally equivalent in the state-level data we used, but in that paper we argued that the substitution or displacement hypothesis was more consistent with other previous research.

In contrast to our results, Mattila (1978), using time-series data, finds that enrollment rates of teenagers are positively associated with minimum wages. He also finds that the employment 
rate of enrolled teenagers is not significantly related to minimum wages, but that the employment rate of non-enrolled teenagers is negatively associated with minimum wages. He interprets these results as suggesting that non-enrolled teenagers experience relatively large disemployment effects from minimum wages. This result is consistent with our interpretation that a higher minimum wage leads to some displacement of lower-quality workers. In contrast to our findings, however, Mattila's results suggest that these workers tend to go back to school when this displacement occurs.

Ehrenberg and Marcus (1980 and 1982) take a somewhat different approach to this question. They conclude from other research that minimum wage increases eliminate part-time, low-wage employment opportunities. They hypothesize that minimum wage increases will then reduce enrollment and increase full-time employment of teenagers from poorer families, because these teenagers use part-time employment to finance their education. On the other hand, by eliminating part-time, low-wage jobs, teenagers from higher-income families, who can afford to remain in school without a job, should be more likely to remain in school (and be non-employed). Using cross-section data for white teenagers, grouped by state, from the 1970 Census of Population, they obtain results counter to their expectations. They find that minimum wages are positively associated with employment of teenagers from higher-income families and negatively associated with employment of teenagers from poor families. They interpret this result as consistent with substitution of higher-quality for lower-quality labor. Ehrenberg and Marcus do not find declines in enrollment for those who are apparently disemployed as a result of minimum wage increases, as neither group's enrollment rate appears to be affected by minimum wages. However, these results are largely reversed in individual- level data from the 1966 National Longitudinal Survey of Young Men. In these data, Ehrenberg and Marcus find that minimum wages result in white male teenagers from higher-income families shifting from enrolled/employed 
to enrolled/non-employed, and white male teenagers from poor families shifting from enrolled/employed to non-enrolled/employed. For nonwhite teenagers from higher-income families in the NLS, there are no effects of minimum wages on employment or enrollment outcomes, while for those from poor families, minimum wages appear to induce a switch from enrolled/nonemployed to non-enrolled/employed, hence reducing enrollment rates and increasing employment rates.

Cunningham (1981) builds on this research by analyzing state-level panel data using the 1960 and 1970 U.S. Censuses. ${ }^{6}$ Cunningham also provides a useful additional theoretical perspective on employment and enrollment transitions. Positing that the same worker is more productive in full-time than in part-time work, he argues that minimum wage increases will increase the demand for full-time workers and reduce the demand for part-time workers. This may help to explain some of the declines in enrollment that we have noted, particularly among those who are originally enrolled and employed (presumably part-time), and switch to non-enrolled and employed (presumably full-time). The increase in demand for full-time labor may act as a further incentive to leave school, apart from the increase in demand for higher-quality labor.

Cunningham finds that minimum wages reduce covered sector employment of white teenagers. For males, the reduction in covered sector employment is largely matched by an increase in uncovered sector employment. For females, there are increases in both uncovered sector employment and non-employment. He also finds that minimum wages reduce part-time employment and increase full-time employment of white teenagers of both sexes, with the reduction in part-time employment outweighing the increase in full-time employment. Finally,

${ }^{6}$ Cunningham exploits the panel data by including in models for schooling, employment, and hours outcomes in 1970 the proportion of individuals in the state in each category in 1960. The control variables (such as the coverage-adjusted relative minimum wage) are entered as proportionate changes over the 10 -year period. 
minimum wages reduce school enrollment of white male and female teenagers. ${ }^{7}$

Cunningham's paper is most similar to our earlier work (Neumark and Wascher, 1995), in that it uses panel data on states. In that sense, both papers probably provide more reliable estimates of minimum wage effects on employment and enrollment than do the other studies. However, none of these papers permits the observation of actual individual-level transitions among alternative employment and enrollment activities in response to minimum wage increases.

Observing such transitions offers three advantages: i) it offers a means of validating the state-level results, ii) it allows us to test alternative hypotheses regarding the demand and supply responses to minimum wage increases, and iii) it enables us to examine differential effects at different points of the skill or wage distribution.

\section{The Empirical Approach}

Our empirical approach is to use the panel nature of matched CPS surveys to study the response of transitions among alternative employment and enrollment activities of teenagers to changes in the minimum wage. In particular, we assume that teenagers choose among four activities: in school/not employed (SNE), in school/employed (SE), not in school/employed (NSE), and not in school/not employed (NSNE) ${ }^{8}$ We assume that this choice is influenced by a set of state-level variables $X$, individual-level variables $Z_{k}$, and a person-specific random component $\epsilon_{k}$.

${ }^{7}$ Similarly, Card (1992b) finds that enrollments declined with the 1988 minimum wage increase in California, relative to other labor markets that did not experience a minimum wage increase.

${ }^{8}$ Of course labor market conditions constrain these decisions, so it may be inappropriate to characterize the outcomes as reflecting solely teenagers' choices. One counter-argument is that, in principle at least, a worker displaced from the covered sector can find employment in the uncovered sector. Alternatively, one can interpret our estimates as representing the effects of both teenagers' choices and labor market conditions. The only implication of this is that we should not interpret the multinomial logit model in a utility-maximizing framework. 
In some specifications, state (S) and year (Y) dummy variables are included to account for unobserved, fixed influences common to all individuals within states or years. In addition, in some specifications we include dummy variables $(\mathrm{J})$ for the individual's school/work activity in the previous year to account for individual heterogeneity or state dependence in the determinants of this choice. The utility from each activity (indexed by $j$ ) for individual $k$ in state $i$ and period $t$ is

$$
\mathrm{U}_{\mathrm{kjit}}=\mathrm{X}_{\mathrm{it}} \beta_{\mathrm{j}}+\mathrm{Z}_{\mathrm{kit}} \gamma_{\mathrm{j}}+\mathrm{J}_{\mathrm{kit}-1} \pi_{\mathrm{j}}+\mathrm{S}_{\mathrm{i}} \delta_{\mathrm{j}}+\mathrm{Y}_{\mathrm{t}} \theta_{\mathrm{j}}+\epsilon_{\mathrm{kit}}
$$

Assuming that $\epsilon_{\mathrm{k}}$ has an extreme-value distribution, this leads to a multinomial logit model. Included in $Z_{k}$ are dummy variables for age (single years), race, and sex. Included in $X$ are the state unemployment rate for males aged 25-64 and the higher of the state or federal minimum wage level, divided by the mean wage in the state. ${ }^{9}$ Although it is common in the literature to multiply this minimum wage variable by the coverage rate, reliable estimates of coverage of teenagers by state and federal minimum wage laws are problematic, and over our sample period (1979-1992) there were no major changes in coverage laws. Thus, although we present some of the results using the coverage-adjusted variable, we highlight results using the minimum wage variable without this additional adjustment. Finally, given evidence from the U.S. and Canada that minimum wage effects occur with a lag (Baker, et al., 1994; Mincer, 1976; Neumark and Wascher, 1992), some specifications substitute the lagged for the contemporaneous minimum wage variable.

We typically report the results for equation (1) after transforming the estimates into derivatives of the probability of each activity with respect to the minimum wage variable. Expressing equation (1) in general form as

$$
\mathrm{U}_{\mathrm{kj}}=\mathrm{W} \alpha_{\mathrm{j}}+\epsilon_{\mathrm{k}}
$$

${ }^{9}$ Initially we included the proportion of teenagers in the population, but its estimated coefficients were insignificant, and its exclusion did not affect the results. 
with $\alpha$ normalized to zero for one of the activities, the derivative of the probability of activity $\mathrm{j}$ with respect to the mth element of $\mathrm{W}$ is calculated as

$$
\partial \mathrm{P}_{\mathrm{j}} / \partial \mathrm{W}_{\mathrm{m}}=\mathrm{P}_{\mathrm{j}}\left\{\alpha_{\mathrm{mj}}-\Sigma_{\mathrm{j}}\left(\mathrm{P}_{\mathrm{j}} \alpha_{\mathrm{mj}}\right)\right\}
$$

where $P_{j}$ is the probability of activity $j$, defined as

$$
P_{j}=\exp \left(W \alpha_{j}\right) /\left\{1+\Sigma_{j} \exp \left(W \alpha_{j}\right)\right\}
$$

We compute standard errors for these derivatives based on a first-order Taylor series approximation of equation (3) around the true values of the $\alpha$ 's (see, e.g., Greene, 1993). It is normally sufficient to evaluate the derivatives and standard errors at the sample means (treating these means as fixed). In our case, however, we are interested in minimum wage effects on transitions among school/work activities, and so we also evaluate these derivatives conditional on the initial activity. We do this by setting the dummy variable (i.e., the element of J) corresponding to the initial activity to one, and the others to zero, in equation (4). As the equation shows, in such calculations the effect of the minimum wage on the probability of any particular transition is influenced by the level of the minimum wage variable.

We also explore, in the context of equation (1), whether there are more direct effects of the minimum wage on the relative probabilities of alternative school/work transitions, by introducing a set of interactions between the dummy variables in $\mathrm{J}$ and the minimum wage variable. ${ }^{10}$ We also estimate versions of equation (1) that allow different effects of minimum wages for various subgroups of teenagers. For example, to test the prediction that disemployment effects of minimum wages should be stronger for individuals initially paid below the new minimum wage, we estimate a model allowing separate effects for these individuals.

\footnotetext{
${ }^{10}$ In principle we could introduce a larger set of interactions of all of the variables with the lagged activity. The most flexible such specification is to estimate a separate multinomial logit model for individuals in each initial activity. When we did this, the estimates were extremely imprecise.
} 


\section{The Data}

The data are taken from the May Current Population Surveys for the period 1979 through 1992. ${ }^{11}$ As is well known, the sample design of the CPS permits a match of some individuals for the same months across two consecutive years (Welch, 1993). We performed this match for all rotation groups $(1,2,3$, and 4 matched with $5,6,7$, and 8 respectively), using the household number, line number, age, sex, and race to identify individuals within the household. The sample is limited to individuals who were between 16 and 19 years old in the first year of the matched records. The resulting data set contains 36,021 matched records, with observations in each state for the periods $1979-1980$ through $1991-1992 .{ }^{12}$ The records include employment and enrollment status, with the former taken from the employment status recode, and the latter from the major activity in the survey week. The matched records were then merged with state-year data on minimum wage levels and state economic characteristics.

One reservation regarding the data is that not all individuals are successfully matched across the CPS surveys. About 65 percent of the eligible teenagers in each year could be matched to a record in the following year, with the match rate slightly higher for the younger ages (Welch, 1993). This raises the possibility of sample selection biases, if unobservable characteristics associated with both successful matches and school/work outcomes are correlated with the independent variables. Such correlations cannot be assumed away, because the probability of

\footnotetext{
${ }^{11}$ We used the May CPS's to maximize comparability with our earlier research. In addition, restricting attention to the same calendar month avoids problems attributable to employment and enrollment changes associated with particular months of the year (such as the beginning and end of summer vacation). However, this problem may influence the May numbers for college students, because the college academic year often ends in May. The inclusion of year dummy variables should mitigate this problem, by capturing the effect of timing changes in the CPS survey week, which is defined as the week that includes the 12th day of the month.

${ }^{12} 1985-1986$ is excluded because the household identifier changed from 1985 to 1986 , making it impossible to match records across these years.
} 
match is related to employment and labor force status (Flaim and Hogue, 1985), and these, in turn, may be influenced by minimum wages. Below, we present some evidence on the role of sample selection bias induced by the matching.

\section{Results}

\section{Simple Comparisons}

Before turning to the multinomial logit estimates, we report in Table 1 some simple comparisons of rates of transition between alternative school/work activities, distinguished by whether the minimum wage increased in the previous year for the state-year observation. For these simple comparisons we discard observations with minimum wage increases less than \$.10. Panel A reports results for all observations. The first matrix shows the proportions making each transition in states/years with no minimum wage increase, while the second shows the same proportions for states/years with a minimum wage increase. The third matrix reports the differences between these proportions, and indicates whether these differences are statistically significant.

The substitution hypothesis predicts that we should see more of at least some of the following transitions when states raise their minimum wages: SNE to SE, SNE to NSE, SE to NSE, and NSE to NSNE. The first three of these transitions represent individuals enrolled in school increasing their labor force attachment, either by leaving school in order to work (SNE to NSE) or to work more (SE to NSE), or by taking a job while remaining in school (SNE to SE). The last of these (NSE to NSNE) represents employed individuals who are displaced from employment and become non-enrolled and non-employed. In addition, we would expect to see fewer transitions from NSNE to NSE and more individuals remaining NSNE as employment opportunities for non-employed less-skilled individuals decline. Of these six predictions, one is 
rejected and five are confirmed. The proportion moving from SNE to SE is significantly lower (by .02), rather than higher, following minimum wage increases. But the proportions moving from SE to NSE and from NSE to NSNE are significantly higher following minimum wage increases, as is the proportion moving from SNE to NSE (although only at the ten-percent significance level). Moreover, the proportion moving from NSNE to NSE is lower in states/years with minimum wage increases, while the proportion remaining NSNE is higher. The queuing hypothesis predicts that the proportions moving from SNE to NSNE and from SE to NSNE should be higher following minimum wage increases. Both of these proportions are higher by .01 , although only the first is significant (at the ten-percent level).$^{13}$

Although minimum wages appear to be associated with transitions from SE to NSE and transitions from NSE to NSNE, those who make the transition from SE to NSE are likely to displace those originally NSE only if their hours increase when they leave school. This is in fact the case. Table 2 reports average hours worked for individuals in each possible combination of year 1 and year 2 activities. In our sample, average weekly hours of individuals who switched from SE to NSE increased by 11.8 , from 19.0 to 30.8 , whereas average weekly hours of those who remained SE increased only from 16.3 to 17.6 , and average weekly hours of those who were NSE in both periods rose from 32.9 to 35.2 .

For purposes of comparison, Panel B of Table 1 shows the same transition matrices using current rather than lagged minimum wage increases. The estimated differences in the proportions making each transition are smaller and are more likely to be significant only at the ten-percent level. However, the sign pattern is very similar to Panel A. Four of the six predictions of the substitution hypothesis are confirmed: the proportion moving from SNE to NSE, the proportion

${ }^{13}$ Holzer, et al. (1991) provide evidence of queuing for minimum wage jobs. 
moving from NSE to NSNE, and the proportion remaining NSNE are higher in the wake of minimum wage increases, while the proportion moving from NSNE to NSE is lower. There is no evidence in favor of the other two predictions of the substitution hypothesis, or the predictions of the queuing hypothesis.

The substitution hypothesis implies that the disemployment effects of minimum wages should be concentrated among low-wage workers who are more likely to be priced out of the market by minimum wage increases. On the other hand, that hypothesis also suggests that higherwage workers, who are more productive and earn more than the minimum, may experience relative demand increases and would therefore be more likely to increase their hours of work. Therefore, we next report some simple comparisons for high- and low-wage workers considered separately. For this analysis, we have to restrict the sample to individuals working for a wage in their first year (either SE or NSE), and for whom wages are reported (outgoing rotation groups). This reduces the sample to approximately one-ninth of its original size.

Panels $\mathrm{C}$ and $\mathrm{D}$ report results for workers above and below the median wage, respectively, in year 1. The substitution hypothesis suggests that, among the high-wage workers, we should see a greater proportion making the transition from SE to NSE following minimum wage increases. In Panel $\mathrm{C}$ this proportion is higher, but the difference is only .01 and is not significant. The substitution hypothesis also suggests that the proportion moving from NSE to NSNE following minimum wage increases should be higher among low-wage workers. This is the case. In Panel $\mathrm{D}$, the proportion making this transition is (significantly) higher by .07 following minimum wage increases, whereas the difference is only .04 (also significant) for high-wage workers.

In Panels $\mathrm{E}$ and $\mathrm{F}$ we use a different approach to the same question, by distinguishing workers based on whether their wage in year 1 was above or below the minimum wage in year 2 . In order to make this comparison, we can only consider current minimum wage increases, since 
we have only two years of data on each individual. Some of these results also support the substitution hypothesis. The proportion moving from NSE to NSNE is significantly higher in states with minimum wage increases for those whose initial wage is below the new minimum, while among those workers with initial wages above the new minimum, there is no difference in the proportion making this transition. On the other hand, among high-wage workers the proportion making the transition from SE to NSE is lower, rather than higher, for states that increased their minimum, which is inconsistent with the substitution hypothesis.

On balance, these simple comparisons provide some evidence that minimum wages reduce employment among the lowest-wage workers, and induce some individuals to leave school for employment or perhaps to increase their hours. In the sections that follow, we explore these questions using the multivariate analysis described in Section III.

\section{Multinomial Logit Estimates of Minimum Wage Effects on School/Work Activities}

In Table 3, we report estimates of minimum wage effects on the probability that an individual is in each of the four school/work activities. For each specification, Panel A reports the estimates of the multinomial logit model, and Panel B reports the implied partial derivatives of the probabilities of being in each activity with respect to the minimum wage. The specification in the first column includes only the lagged minimum wage. The minimum wage variable has a significant positive effect on the probability of being in either of the non-enrolled categories (NSE and NSNE) relative to in school and non-employed (SNE) and a significant negative effect on the probability of being in school and employed (SE) relative to SNE. In column (2) the unemployment rate for men aged $25-64$ is added. The only difference is that the estimated minimum wage effect on the SE/SNE probability is now significant only at the ten-percent level. In column (3) age (single years), race, and sex dummy variables are added. The fit of the model 
improves significantly, while the estimated minimum wage effects are little changed. In column (4) year dummy variables are added. This results in somewhat less precise estimates of the minimum wage effects for two of the three relative probabilities, probably because the year dummy variables eliminate much of the influence of changes in the federal minimum. In particular, the effect on the SE/SNE probability becomes small and insignificant. In column (5) the state dummy variables are added to account for fixed, state-specific differences in the proportions in each school/work activity. The estimated minimum wage effect on the NSE/SNE probability becomes insignificant, while that on the SE/SNE probability reverts to being negative and significant. ${ }^{14}$

To this point, and in most of the empirical analysis in this paper, we do not use the fixed effects multinomial logit model (Chamberlain, 1980). There are two reasons. First, we want to allow separate minimum wage effects for each school/work transition. This requires an interaction between the minimum wage variable and lagged school/work activity, which in the context of the fixed effects model requires at least three observations per person, while we have only two.

Second, the fixed effects model does not allow us to estimate the marginal effects of the minimum wage on the probability of each school/work activity, since the coefficients of time-invariant variables are not estimated. Nonetheless, we are interested in gauging the magnitude of any bias from individual heterogeneity. Therefore, in column (6) we report fixed effects multinomial logit estimates of the model in column (5). Only the estimated minimum wage effect on the NSE/SNE probability changes markedly, and even then, the standard error of the fixed effects estimate is

\footnotetext{
${ }^{14}$ Even if the state dummy variables are uncorrelated with the other variables, the standard errors ought to rise with the addition of these dummy variables, as correlations across errors of individuals in the same state are eliminated (Moulton, 1990). This is the case.
} 
large. ${ }^{15}$

Column (7) instead attempts to account for heterogeneity bias (as well as state dependence) by reverting to the multinomial logit model, but adding dummy variables for lagged activity. The estimated minimum wage effects are quite similar to those in column (5), and the estimated coefficients of the lagged activity variables are strongly significant. To this point, the specification in column (7) is our preferred specification, as each of the sets of variables added in columns (1)(5) and in column (7) enters significantly. ${ }^{16}$

With regard to the partial derivatives shown in Panel B, the results in column (7) indicate that an increase in the minimum wage significantly reduces the probability that an individual is in school and employed (SE) and significantly increases the probability that an individual is neither in school nor employed (NSNE). The overall effect of minimum wages on the probability of enrollment is strongly negative (-.50), while the overall effect on employment is negative but not large $(-.13)$. These estimates are consistent with our results using state-level aggregate data, as reported in Neumark and Wascher (1995).

It is also informative to interpret the estimates in Table 3 in terms of elasticities. For

${ }^{15}$ Because we will improve on the model in column (5) by adding the individual's lagged school/work activity, Hausman tests of the model in column (6) vs. that in column (5) are not of interest. In addition, the models in columns (5) and (6) are not completely comparable because we have to drop dummy variables for two additional years in the fixed effects estimation. The reason is that two linear relationships among the year and age dummy variables arise in the fixed effects specification, because there are no 20 year-olds in 1979 or 1986 , and no 16 year-olds in 1985 or 1992 in our matched data set.

${ }^{16} \mathrm{As}$ is well-known, the multinomial logit model imposes the assumption of the independence of irrelevant alternatives. One way to assess the validity of this assumption is to drop one or more of the choices, and see if the parameter estimates for the remaining choices are changed much (Hausman and McFadden, 1984). We estimated separate logit models for each choice relative to the SNE category. In all cases, the parameter estimates were very similar to those obtained from the full multinomial logit model. For example, the estimated minimum wage effects (standard errors) on the SE/SNE, NSE/SNE, and NSNE/SNE probabilities, in specifications comparable to those in column (7), were $-1.95(.86), 1.32(.85)$, and $2.49(1.10)$. 
example, in column (7) the estimated partial derivative of the probability of being NSNE with respect to the minimum wage variable is .23 . Since the mean of the minimum wage variable is .43 and the overall proportion of the sample in the NSNE category is .085 , the relevant elasticity is $1.16(\{.23 / .085\} /\{1 / .43\})$. Thus, the effect of a $10 \%$ increase in the minimum wage is to increase the proportion NSNE by $11.6 \%$. A similar calculation implies the following elasticities for the probability of the other school/work activities: SNE (-.10); SE (-.70); and NSE (.57). In addition, the elasticity of net employment (SE + NSE) is -.13 , while the elasticity of net enrollment $(\mathrm{SNE}+\mathrm{SE})$ is -.30 .

In the model in column (7), lagged activity influences the implied derivatives with respect to the minimum wage by altering the point of the distribution at which the probability of each activity is evaluated. (See equation (3).) In column (8), we allow a more explicit dependence of minimum wage effects on lagged activity by including interactions between lagged activity and the minimum wage variable. This specification, however, does not fit the data any better than the model in column (7). In particular, the more restrictive specification in column (7) is not rejected using a likelihood-ratio test, and as we will see below, estimates of the effects of minimum wages on the probabilities of each transition are very similar using the specification in columns (7) and (8).

Table 4 provides some additional sensitivity analyses. First, in column (1) we estimate the model substituting the coverage-adjusted minimum wage variable for the unadjusted variable. The estimated effects on the probabilities of each school/work activity are very similar, although the standard errors are larger. In column (2) we report estimates using the current minimum wage variable instead of the lagged variable. The estimated effects on the probabilities of three of the four activities are smaller, and the log-likelihood is slightly lower. In addition, when the current and lagged values were included together--in columns (3) and (3')--only the effects of the lagged 
values are significant. Consequently, in what follows we use the specification with the lagged relative minimum wage variable, unadjusted for coverage.

Next, we consider the influence of sample selection biases that arise from our inability to match all individuals in consecutive years of the CPS. We address this issue by constructing a parallel sample of non-matched individuals in each year, being careful to keep the characteristics of the sample the same as in the matched data set; in particular, we exclude 20 year-olds in 1979 (the first year of the matched sample) and 1986 (because we cannot match individuals from 1985 to 1986) and 16 year-olds in 1992 (the last year of the matched sample) and 1985 (again, because we cannot match individuals from 1985 to 1986). We then compare estimates of the multinomial logit model for the alternative school/work activities using the matched and non-matched samples. ${ }^{17}$ Because we cannot estimate the model with lagged activities for the non-matched sample, we make this comparison using the specification in column (5) of Table 3, and pool the data across both years for the matched sample.

As a preliminary, the top panel of Table 5 provides descriptive statistics for the matched and unmatched samples. The matched individuals are more likely to be in school (SNE or SE), and less likely to be NSE or NSNE. In addition, of those who are out of school, individuals in the matched sample are relatively more likely to be working (NSE) than not (NSNE). The bottom panel reports estimates of the marginal effects of the lagged minimum wage variable on the probability of being in each activity. The estimated minimum wage effects on the SNE and SE probabilities differ across the two samples. Overall, the sum of the two effects, which is the overall effect on the probability of being in school, is larger for the non-matched sample. The

\footnotetext{
${ }^{17}$ An alternative strategy is to model jointly the school/work activities of the matched sample and the selection process that determines who is matched. However, there is not a great deal of information in the CPS that might be expected to measure exogenous determinants of failure or success at matching.
} 
estimated effects for the NSE and NSNE activities are also larger for the non-matched sample. Thus, these results suggest that the estimated minimum wage effects from the matched sample tend to be biased towards zero, relative to the population parameters. This suggests, in turn, that our estimated minimum wage effects for the matched sample probably understate the true effects, strengthening the evidence for the effects that we find.

\section{Minimum Wage Effects on School/Work Transitions}

We next use the estimates of the multinomial logit model to calculate the implied partial derivative of the probability of each school/work transition with respect to the minimum wage variable. The estimated partial derivatives in Tables 3 and 4 use the sample means of the lagged school/work activity dummy variables to derive $P_{j}$ in equation (4). In contrast, in Table 6 we calculate derivatives of switching to each possible school/work activity, conditional on being in a given initial activity. We therefore set the lagged activity dummy variable equal to one for the initial school/work activity being considered, and set the others to zero. Thus, we calculate 16 partial derivatives (four initial activities $\times$ four final activities), rather than only four.

In Panel $\mathrm{A}$, the derivatives are calculated based on the estimates of the specification in column (7) of Table 3, which omits the interactions between the minimum wage variable and lagged activity. As column (1) reports, for those originally SNE, minimum wage increases significantly reduce the probability of becoming SE and significantly increase the probability of becoming NSNE. The former effect suggests that it is not those who are originally SNE who displace lower-wage workers; the latter effect is consistent with individuals leaving school to queue for minimum wage jobs. The positive (although insignificant) effect on the probability of becoming NSE suggests that some of them find jobs, consistent with displacement.

For those originally SE, column (2) shows that the probability of remaining in this activity 
is significantly reduced by an increase in the minimum wage. There is a large and significant (at the $10 \%$ level) positive effect of the minimum wage on the probability of becoming NSE (not in school/employed), suggesting that such individuals may be displacing less-skilled workers. There is a smaller significant positive effect on the probability of becoming NSNE, consistent with queuing for presumably full-time minimum wage jobs. ${ }^{18}$ Alternatively, the increased probability of becoming NSNE for those originally SE (or SNE) may reflect individuals leaving school for other reasons (including to take a job), and subsequently becoming unemployed. Finally, the estimates imply that a higher minimum reduces the overall probability of enrollment.

For those originally NSE, there is a positive and significant effect of the minimum wage on the probability of becoming NSNE. This effect is consistent with the hypothesis that some previously-employed workers are displaced in response to a minimum wage increase. In addition, a higher minimum wage discourages these individuals from returning to school, significantly so in the case of the SE activity.

Finally, for those originally NSNE, minimum wages significantly increase the probability that they remain in this activity, and significantly reduce the probability of returning to school. This again is consistent with the displacement hypothesis, although in this case individuals face a lack of job opportunities rather than direct job loss.

Panel B of Table 6 reports estimates of the same partial derivatives based on the more flexible specification that includes the minimum wage variable interacted with lagged school/work activity (column (8) of Table 3). Although we previously indicated that this specification did not fit the data any better, these estimates provide some evidence on the robustness of our results.

\footnotetext{
${ }^{18}$ In theory, we could look at whether these individuals are unemployed or out of the labor force to determine whether they are queuing for minimum wage jobs. In practice, the correspondence between the empirical categories and the theoretical constructs is quite tenuous (Clark and Summers, 1982).
} 
Both the point estimates and the standard errors in this specification are larger than in Panel A, but the qualitative conclusions are very similar. ${ }^{19}$

The minimum wage effects documented in Table 6 are consistent with displacement of lower-quality workers by higher-quality workers. This type of displacement may help to explain the relatively low net disemployment effects for teenagers in standard employment regressions.

For teenagers, there appears to be a relatively strong supply response to higher wages for higherquality workers. These findings may also explain why, for young adults (aged 16-24) as a whole, disemployment effects are stronger in standard employment regressions (Neumark and Wascher, 1992 and 1994b). Among the older individuals in this age group, the potential for a supply response is probably lower. That is, with the initial employment rate considerably higher (and the initial school enrollment rate lower), there is probably a smaller pool of higher-skilled or higherquality workers who might enter the labor market in response to higher wages.

\section{Additional Evidence on Queuing}

There is some evidence in Table 6 of both a queuing response and a substitution response to minimum wages. One possible interpretation of queuing is that in response to a minimum wage increase, teenagers leave school, and possibly even leave the in-school, employed activity, to queue for (presumably full-time) minimum wage jobs. An alternative explanation is that some individuals leave school in any event, but those in states where minimum wages have risen find it

\footnotetext{
${ }^{19} \mathrm{We}$ also estimated these partial derivatives for some other specifications. First, using the coverage-adjusted relative minimum wage variable, the point estimates and statistical inferences were virtually unchanged. Second, when both the current and lagged values of the relative minimum wage variable were included, none of the contemporaneous effects were significant. On the other hand, nearly all of the lagged effects that were significant when only the lagged minimum wage was included continued to be significant when both the lagged and contemporaneous minimum wage were included, and the implied minimum wage effects were similar.
} 
harder to obtain a job, and are therefore more likely to end up NSNE. However, this cannot be the whole story, since this interpretation cannot explain why enrollment rates decline in response to minimum wage increases. We have no way of assessing, using the CPS data, whether minimum wage increases actually changed individuals' schooling plans. However, we can perhaps shed some light on these alternative interpretations by examining whether the in-school (SNE or SE) to NSNE transition is more likely to occur among those with less than 12 years of schooling in year 1, than among those with 12 or more years of schooling. It seems plausible that those who make this transition prior to completing high school were more likely to have dropped out of school in response to minimum wage increases.

Panel A of Table 7 shows the distribution by years of schooling in year 1 for those making the transition from either SNE or SE to NSNE. The first two columns show these distributions for states/years with no minimum wage increase, while the second two columns show these distributions for states/years in which minimum wages increased; the final two columns show the differences. The results indicate that in states/years in which minimum wages increased, a larger proportion of individuals leaving school and becoming NSNE had less than 12 years of schooling. The difference is positive both for those originally SNE and those originally SE, although significant only for the latter. These results suggest that the higher flow from SNE or SE to NSNE in the wake of minimum wage increases may stem from individuals dropping out of high school. But they do not demonstrate this conclusively. We may also be observing that highschool dropouts have a relatively harder time finding jobs after minimum wage increases, with the decision to drop out not influenced by minimum wages.

As additional evidence, Panel $\mathbf{B}$ of the table focuses on individuals leaving school regardless of their year 2 activity (i.e., moving from SNE or SE to NSE or NSNE). In states/years with minimum wage increases, the proportion of those leaving school with less than 12 
years of education is significantly higher than in states/years without minimum wage increases (.34 vs. .31), and the proportions with 12 or more years of schooling are correspondingly lower. This provides more direct evidence that individuals are actually leaving school to queue for minimum wage jobs, because, unlike in Panel A, the differences cannot be attributed to a differential distribution of those with more or less schooling among the NSE and NSNE activities (in year 2).

But even the evidence in Table 7 is not conclusive. It does give some credence to the queuing hypothesis, since those making the transition from school to NSNE are weighted slightly toward those with less than 12 years of schooling. At the same time, however, individuals with more than 12 years of schooling also appear to move from school to NSNE in response to minimum wage increases. Of course, these individuals could also be reducing their schooling relative to the amount they would have gotten in the absence of a minimum wage increase. Ultimately, in the absence of data on schooling plans and realizations, we think it is difficult to determine decisively whether individuals leaving school to become NSNE are literally leaving school to queue for minimum wage jobs, or instead entering the labor market according to plans, and finding it more difficult to obtain employment.

Minimum Wage Effects on School/Work Transitions, Disaggregated by Age

To this point, we have not used the multinomial logit framework to estimate minimum wage effects on subgroups of teenagers differentiated by skill or wages. We now turn to a number of such experiments. Because age may be a proxy for quality, we first calculate separate estimates for 16-17 year-olds and 18-19 year-olds. These results, which are based on separate estimates of the multinomial logit model for each age group, are reported in Table $8 .{ }^{20}$ We find considerably

\footnotetext{
${ }^{20}$ Given the lack of sensitivity of the results to the inclusion of interactions between the minimum wage variable and lagged school/work activity, the use of the coverage adjustment, and
} 
smaller effects of minimum wages on the probability of leaving school for employment for 16-17 year-olds than for 18-19 year-olds. For the 16-17 year-olds, none of the estimated effects on the probability of moving from SNE to either SE or NSE, or from SE to NSE, are significant. For 18-19 year-olds, the most striking result is a large (.64) and significant positive effect on the probability of moving from SE to NSE. On the other hand, we find larger effects of moving from NSE to NSNE for 16-17 year-olds, for whom the estimate is .24 and significant, than for 18-19 year-olds, for whom the estimate is .16 and insignificant.

Assuming that age is an indicator of skill level, these results are consistent with the hypothesis that more-skilled workers displace less-skilled workers following a minimum wage increase. In particular, some 18-19 year-olds leave school and become employed full-time, while some 16-17 year-olds who were initially NSE become disemployed, and apparently choose not to return to school. ${ }^{21}$

\section{Minimum Wage Effects on School/Work Transitions, Disaggregated by Race}

A similar experiment in which we disaggregate the effects by race or ethnicity is of interest, because for a number of reasons (including lower-quality schools or discrimination), employers might regard blacks and Hispanics as less-skilled workers than non-black, non-Hispanic workers. Thus, in Table 9 we report estimates of minimum wage effects on transitions among school/work activities from separate estimates of the multinomial logit model by race.

The effects of minimum wages on the transition from NSE to NSNE are significant for both subgroups, but five times as large for black or Hispanic teenagers (.51 vs. .10). In addition,

the inclusion of the current minimum wage variable, from this point on we use the specification from column (7) of Table 3 which omits each of these.

${ }^{21}$ Consistent with this hypothesis, the average weekly hours of those 18-19 year-olds who go from SE to NSE increase from 20.1 to 32.8 . 
minimum wages have a significant positive effect on the probability that non-black, non-Hispanic teenagers move from SE to NSE, but a smaller and insignificant effect for black or Hispanic teenagers. Thus, these results suggest that minimum wage increases result in non-black, nonHispanic teenagers leaving school to work full-time, displacing black or Hispanic teenagers who were previously employed full-time, and who subsequently become neither enrolled nor employed. These results also suggest that blacks or Hispanics are most likely to become disemployed following a minimum wage increase. If black or Hispanic teenagers also are less skilled, on average, than non-black, non-Hispanic teenagers, or are perceived as such by employers, then this evidence provides further corroboration of the substitution hypothesis.

Minimum Wage Effects on School/Work Transitions, Disaggregated by Initial Wage Relative to New Minimum Wage

Our final set of estimates use initial wage levels as a proxy for skill by distinguishing the effects of minimum wages for individuals originally above or below the new minimum wage. Because the displacement suggested by the preceding results should be concentrated among lowwage workers who are effectively priced out of the market by minimum wage increases, distinguishing the effects for workers above and below the new minimum should give us more reliable estimates of such effects. In addition, this exercise provides a separate test of whether we are actually detecting minimum wage effects by focusing on the group directly affected by minimum wage laws. Finally, the displacement and queuing hypotheses have somewhat different implications for the effects of minimum wages on other transitions, depending on whether an individual's wage is above or below the new minimum.

Because we have only two years of data on each person, we alter the specification slightly, 
using the current minimum wage, and comparing it to the individual's lagged wage. ${ }^{22}$ We estimate the model including a dummy variable for individuals whose wage in year 1 is below the current minimum, and an interaction of this variable with the dummy variables for lagged school/work activity. Note also that the sample sizes are reduced significantly, owing to the limited sample for which we have wage data.

For purposes of comparison, columns (1) and (2) of the table report the estimated effects of the contemporaneous minimum wage variable, for the two initial activities entailing employment. These are little different from the estimates in column (7) of Table 3, although, as noted earlier, they are smaller. Columns (3) and (4) report results for individuals with a year 1 wage that is below the minimum wage level in year 2 , while columns (5) and (6) report results for those at or above the new minimum.

For workers below the new minimum, minimum wages increase the probability of becoming NSNE for workers initially in either school/work activity. The large (.50) increase in the probability that an NSE individual becomes NSNE (significant at the $10 \%$ level) is consistent with displacement of lower-quality workers. A similar but smaller (.22) effect for those originally SE is more difficult to explain as displacement, since it is not obvious why these individuals leave school. One possibility is that they leave school to queue for full-time minimum wage jobs, assuming that the switch to full time will raise their productivity and make them employable at the new minimum. Another possibility is that they would have left school in any case, but because of the minimum wage increase, are less likely to end up NSE and more likely to end up NSNE.

In contrast, for those earning at or above the new minimum wage, there are no significant effects of minimum wages on the probability of becoming NSNE. This is as expected. These years back.

${ }^{22}$ We have no way of comparing the lagged minimum wage to the individual's wage two 
workers should not be displaced by minimum wage increases, nor should they leave school to queue for minimum wage jobs, since they already earn more than the minimum. However, the substitution hypothesis predicts that these workers leave school (SE) to become full-time workers. The estimated effect for this transition is positive (.44), but not significant.

A potential problem with the estimates in Table 10 is that some workers whose wages are below the new minimum may also earn less than the old minimum, because they are not covered by minimum wage laws, or are waitpersons for whom a tip credit can be applied toward the minimum wage. In either case, changes in minimum wages may affect these workers differently. We therefore estimate a specification in which we distinguish effects for those below the old minimum. We also allow separate effects for those at the old minimum, and those between the old and the new minimum. This is potentially informative for two reasons. First, those earning above the old minimum (but below the new) are presumably of higher quality than those earning the old minimum, and we have suggested that minimum wage effects may differ for workers of different quality. Second, employers of workers clustered at the old minimum wage may have already exhausted ways of changing employment levels of other inputs (including other types of labor) or adjusting non-wage compensation, so that a further minimum wage increase is more likely to make such workers unemployable. ${ }^{23}$ In contrast, for those above the old minimum, such adjustments may not yet have occurred. ${ }^{24}$

\footnotetext{
${ }^{23}$ Meyer and Wise (1983), for example, suggest that nonwage compensation may adjust downward in response to minimum wage increases, leading to a spike in the wage distribution at the minimum wage. However, Card and Krueger (1994) examine the effects of minimum wages in the fast-food industry on the provision of a particular form of non-wage compensation--the provision of free or reduced-price meals--and find no significant reduction in this benefit associated with higher minimum wages. Obviously, this result cannot necessarily be generalized beyond the fast-food industry, or to other benefits in that industry.

${ }^{24}$ James Spletzer originally suggested to us that minimum wage effects on employment may differ for those at the old minimum and those above the old but below the new minimum.
} 
The estimates are reported in Table 11. Overall, many of the effects are estimated rather imprecisely. However, we do find that for those at the old minimum, the estimated minimum wage effects on the probability of becoming NSNE are very similar to those in Table 10. At the same time, the estimates of this effect for those below the old minimum are not significant, nor are the estimates for those above the old but below the new minimum.

\section{Simulated Hours Changes}

To this point, we have documented the changes in enrollment and employment status that result from changes in the minimum wage. These changes suggest that the employment rate falls. In Table 3, for example, the net effect of the minimum wage on the probability of being SE or NSE is negative, and in Table 6 the probability of a transition to SE is reduced by more than the probability of a transition to NSE is increased, for each of the initial employment-enrollment activities. However, since hours of those who are NSE are higher than hours of those who are $\mathrm{SE}$, it is not immediately obvious that the overall amount of labor employed, measured in terms of hours, falls. Roughly speaking, there are two effects. Some workers go from SE to NSE, increasing their hours, while others go from NSE to NSNE, decreasing their hours. Although the latter effect entails a larger absolute change in hours, the minimum wage has a larger effect on the probability of the transition from SE to NSE, because the estimated partial derivative is larger (in absolute value) for this transition, and because the proportion SE in year 1 is larger than the proportion NSE. Therefore, the net effect on hours is ambiguous. In this section, we present some simple calculations to simulate the hours changes. Our goal is not to provide a thorough analysis of the effects of minimum wages on hours worked; we leave that task to future research. Rather, we seek only to interpret the changes in the incidence of enrollment and employment that we document in terms of changes in the overall "volume" of employment. 
First, we calculate the average weekly hours of individuals in year 1 and year 2 for each of the possible pairs of enrollment and employment activities in the two years. These were reported in Table 2. For example, those who go from SE to NSE have average weekly hours of 19.0 in year 1 , and 30.8 in year 2 . We assume that the hours changes associated with each transition are independent of minimum wages (and other variables), and calculate the implied average hours change caused by a minimum wage increase by applying the estimated minimum wage effects on the probability of each transition to the hours changes in Table $2 .{ }^{25}$ Overall, the implied derivative of average weekly hours with respect to the minimum wage variable is -4.86 , suggesting that hours do in fact fall in response to minimum wage increases. Since average weekly hours (including those who work zero hours) are 23.5 , this implies an elasticity of -.09 .

We also computed hours changes for 16-17 year-olds and 18-19 year-olds separately. The overall patterns of hours changes are similar for the two age groups. Thus, the estimated changes in hours following a minimum wage increase hinge more on differences in the estimated effects of minimum wages on the probabilities of alternative employment and enrollment transitions.

Looking back to Table 8 , we see that--in response to a minimum wage increase--16-17 year-olds have a higher probability of moving from NSE to NSNE, entailing a large hours reduction, while 18-19 year-olds have a higher probability of moving from SE to NSE, with an hours increase. This is reflected in the simulated hours changes. For 16-17 year-olds the implied change in average weekly hours is -13.87 , while for $18-19$ year-olds it is only $-2.41 .{ }^{26}$ Thus, $16-17$ yearolds appear to bear the brunt of the hours reduction from minimum wage increases, which is

\footnotetext{
${ }^{25}$ Thus, for example, going down the columns of Tables 2 and 6 , the first few terms in this calculation are $(-.09)(0)+(-.29)(15.8)+(.17)(29.3) \ldots$

${ }^{26}$ Note that these two figures need not be a weighted average of the figure for 16-19 yearolds considered together, since the calculations for the separate age groups are based on separate estimates of the multinomial logit model.
} 
consistent with displacement by older, more-skilled workers.

\section{Conclusions}

The recent debate over minimum wages raises two questions. First, should policy makers no longer believe that minimum wages entail negative consequences for teenagers? Second, should economists discard the competitive labor market model? Our evidence suggests that the answer to both of these questions is no.

Our results can be summarized as follows. First, an increase in the minimum wage increases the probability that teenagers leave school. Some of these teens do not become employed, which we interpret as consistent with the hypothesis that there is queuing for minimum wage jobs. Others do find employment, but apparently at the expense of less-skilled workers--such as minorities and 16-17 year-olds--who are displaced from their jobs. In addition, our evidence indicates that an increase in the minimum wage raises the probability that these less-skilled employed teenagers become non-enrolled and non-employed, and raises the probability that lessskilled non-employed teenagers remain out of the work force.

Thus, although minimum wages may lead to small net disemployment effects for teenagers as a group, there are significant enrollment and employment shifts associated with minimum wage changes that should be of concern to policy makers. The evidence also suggests that the conventional view of minimum wage effects is largely correct. The standard textbook model refers to homogeneous workers initially earning less than the minimum. But in a model with heterogeneous workers, only those with a market wage at or near the minimum should be disemployed by a higher minimum wage. Moreover, the net disemployment effect for all teenagers may be small if there is substitution toward more-skilled workers. Our evidence is consistent with this model. 
Finally, the evidence we present supports the view that the disemployment effects of minimum wages fall largely on less-skilled workers. In this sense, the conventional findings of an employment elasticity with respect to minimum wages of -.1 to -.2 are somewhat misleading. This elasticity is generally interpreted to mean that a ten-percent increase in the minimum wage reduces the employment rate of teenagers by 1 percent. While strictly correct, there is a sense in which this compares apples to oranges. For the most part, a minimum wage increase raises the wages only of lower-wage workers; however, this same group experiences the largest employment declines. The conventional elasticity, then, is effectively the ratio of the employment decline averaged across all workers to the wage increase among lower-wage workers. A more relevant measure would be the ratio of the employment decline among lower-wage workers to the wage increase among lower-wage workers (i.e., the minimum wage increase). Or, we could compute the ratio of the employment decline averaged across all workers to the wage increase averaged across all workers. The first calculation entails a larger negative number in the numerator, while the second entails a smaller positive number in the denominator. Either calculation, however, suggests that the commonly reported elasticities mask stronger disemployment effects for those same workers whom minimum wages are intended to help. 


\section{$\underline{\text { References }}$}

Abowd, John M., and Mark R. Killingsworth. 1981. "Structural Models of the Effects of Minimum Wages on Employment by Age Groups." Report of the Minimum Wage Study Commission, pp. 143-69.

Baker, Michael, Dwayne Benjamin, and Shuchita Stanger. 1994. "The Effects of Minimum Wages in the Canadian Labour Market: 1975-1993." Mimeograph, University of Toronto.

Brown, Charles. 1988. "Minimum Wage Laws: Are They Overrated?" Journal of Economic Perspectives, Vol. 2, No. 3, Summer, pp. 133-46.

Brown, Charles, Curtis Gilroy, and Andrew Kohen. 1983. "The Effect of the Minimum Wage on Employment and Unemployment." Journal of Economic Literature, Vol. 20, June, pp. 487-528.

Card, David. 1992a. "Using Regional Variation in Wages to Measure the Effects of the Federal Minimum Wage." Industrial and Labor Relations Review, Vol. 46, No. 1, October, pp. 22-37.

. 1992b. "Do Minimum Wages Reduce Employment? A Case Study of California, 19871989." Industrial and Labor Relations Review, Vol. 46, No. 1, October, pp. 38-54.

Card, David, and Alan. B. Krueger. 1994. "Minimum Wages and Employment: A Case Study of the Fast-Food Industry in New Jersey and Pennsylvania." American Economic Review, Vol. 84, No. 4, September, pp. 772-93.

Castillo-Freeman, Alida, and Richard Freeman. 1992. "When the Minimum Wage Really Bites: The Effect of the U.S.-Level Minimum on Puerto Rico." In George Borjas and Richard Freeman, Eds., Immigration and the Work Force (Chicago: University of Chicago Press), pp. 177-212.

Chamberlain, Gary. 1980. "Analysis of Covariance with Qualitative Data." Review of Economic Studies, Vol. 47, No. 1, February, pp. 225-38.

Clark, Kim, and Lawrence Summers. 1982. "The Dynamics of Youth Unemployment." In Richard Freeman and David Wise, Eds., The Youth Labor Market Problem: Its Nature, Causes and Consequences (Chicago, IL: University of Chicago Press), pp. 199-235.

Cunningham, James. 1981. "The Impact of Minimum Wages on Youth Employment, Hours of Work, and School Attendance: Cross-Sectional Evidence from the 1960 and 1970 Censuses." In S. Rottenberg, Ed., The Economics of Legal Minimum Wages (Washington, D.C.: American Enterprise Institute), pp, 88-123.

Currie, Janet, and Bruce Fallick. 1993. "A Note on the New Minimum Wage Research." NBER Working Paper No. 4348.

Ehrenberg, Ronald G., and Alan J. Marcus. 1982. "Minimum Wages and Teenagers' Enrollment-Employment Outcomes." Journal of Human Resources, Vol. 17, No. 1, Winter, pp. 39-58. 
in Labor Economics, Vol. 3, pp. 61-93.

Flaim, Paul O., and Carma R. Hogue. 1985. "Measuring Labor Force Flows: A Special Conference Examines the Problems." Monthly Labor Review, pp. 7-17.

Gramlich, Edward M. 1976. "Impact of Minimum Wages on Other Wages, Employment, and Family Incomes." Brookings Paper on Economic Activity, No. 1, pp. 409-51.

Greene, William H. 1993. Econometric Analysis (New York: Macmillan Publishing Company).

Hausman, Jerry, and Daniel McFadden. 1984. "A Specification Test for the Multinomial Logit Model." Econometrica, Vol. 52, pp. 1219-1240.

Holzer, Harry J., Lawrence F. Katz, and Alan B. Krueger. 1991. "Job Queues and Wages." Quarterly Journal of Economics, Vol. 106, No. 3, pp. 739-68.

Katz, Lawrence F., and Alan B. Krueger. 1992. "The Effect of the Minimum Wage on the Fast-Food Industry." Industrial and Labor Relations Review, Vol. 46, No. 1, October, pp. 6-21.

Kim, Taeil, and Lowell J. Taylor. 1995. "The Employment Effect in Retail Trade of California's 1988 Minimum Wage Increase." Forthcoming in Journal of Business and Economic Statistics.

Krueger, Alan B. 1994. "The Effect of the Minimum Wage When It Really Bites: A Reexamination of the Evidence from Puerto Rico." NBER Working Paper No. 4757.

Machen, Stephen, and Alan Manning. 1994. "The Effects of Minimum Wages on Wage Dispersion and Employment: Evidence from the U.K. Wage Councils." Industrial and Labor Relations Review Vol. 47, No. 2, January, pp. 319-29.

Mattila, J. Peter. 1978. "Youth Labor Markets, Enrollments, and Minimum Wages." Proceedings of the Thirty-First Annual Meeting, Industrial Relations Research Association Series, pp. 134-40.

Meyer, Robert H., and David A. Wise. 1983. "The Effects of the Minimum Wage on the Employment and Earnings of Youth." Journal of Labor Economics, Vol. 1, No. 1, January, pp. 66-100.

Mincer, Jacob. 1976. "Unemployment Effects of Minimum Wages." Journal of Political Economy, Vol. 84, No. 3, Pt. 2, pp. S87-S104.

Moulton, Brent R. 1990. "An Illustration of a Pitfall in Estimating the Effects of Aggregate Variables on Micro Units." Review of Economics and Statistics, Vol. 72, No. 2, May, pp. 334-8.

Neumark, David, and William Wascher. 1995. "Minimum Wage Effects on Employment and School Enrollment." Forthcoming in Journal of Business and Economic Statistics.

. 1994a. "Minimum Wage Effects and Low-Wage Labor Markets: A Disequilibrium Approach." NBER Working Paper No. 4617. 
1994b. "Employment Effects of Minimum and Subminimum Wages: Reply to Card,

Katz, and Krueger." Industrial and Labor Relations Review, Vol. 47, No. 3, April, pp. 497-512.

1992. "Employment Effects of Minimum and Subminimum Wages: Panel Data on State Minimum Wage Laws." Industrial and Labor Relations Review, Vol. 46, No. 1, October, pp. 5581.

Spriggs, William E. 1992. "Changes in the Federal Minimum Wage, a Test of Wage Norms." Mimeograph, Economic Policy Institute.

Welch, Finis. 1993. "Matching the Current Population Surveys." In Joseph Hilbe, Editor Stata Technical Bulletin Reprints, Volume 2 (Santa Monica, CA: Computing Resource Center), pp. 3440 .

Wellington, Alison J. 1991. "Effects of the Minimum Wage on the Employment Status of Youths: An Update." Journal of Human Resources, Vol. 26, No. 1, Winter, pp. 27-46.

Williams, Nicolas. 1993. "Regional Effects of the Minimum Wage on Teenage Employment." Applied Economics, Vol. 25, pp. 1517-28. 
Table 1

Probabilities of Transitions: Minimum Wage Increases

\section{A. All Observations (Lagged Minimum Wage Increases)}

No Increase

In Minimum Wage

\begin{tabular}{|c|c|c|c|c|c|c|c|c|c|}
\hline & & & & & & \\
\hline Yr 2: & Yr 1: & SNE & $\mathrm{SE}$ & NSE & NSNE & SNE & SE & NSE & NSNE \\
\hline$\overline{\text { SNE }}$ & & .58 & .25 & .12 & .17 & .58 & .26 & .13 & .17 \\
\hline SE & & .18 & .43 & .12 & .05 & .16 & .40 & .10 & .05 \\
\hline NSE & & .15 & .27 & .66 & .31 & .16 & .30 & .64 & .29 \\
\hline NSNE & & .09 & .05 & .11 & .46 & .10 & .05 & .13 & .49 \\
\hline $\mathrm{N}$ & & 9450 & 4656 & 3547 & 1584 & 7714 & 3973 & 3500 & 1453 \\
\hline
\end{tabular}

Difference (Increase - No Increase)

$\begin{array}{cccc}\text { SNE } & \text { SE } & \text { NSE } & \text { NSNE } \\ .01 & .01 & .01^{* *} & .00 \\ -.02^{* *} & -.03^{* *} & -.02^{* *} & .00 \\ .01^{*} & .02^{* *} & -.02^{*} & -.03^{*} \\ .01^{* *} & .01 & .02^{* *} & .03^{* *}\end{array}$

\section{B. All Observations (Current Minimum Wage Increases)}

\begin{tabular}{|c|c|c|c|c|c|c|c|c|c|c|c|c|}
\hline Yr 2: & Yr 1: SNE & SE & NSE & NSNE & SNE & SE & NSE & NSNE & SNE & SE & NSE & NSNE \\
\hline$\overline{\text { SNE }}$ & .58 & .26 & .12 & .17 & .57 & .25 & .11 & .17 & -.01 & -.00 & -.00 & .00 \\
\hline SE & .17 & .41 & .11 & .05 & .17 & .42 & .10 & .05 & .00 & .01 & $-.01^{*}$ & .00 \\
\hline NSE & .15 & .29 & .65 & .31 & .16 & .28 & .65 & .28 & $.01^{* *}$ & -.01 & .00 & $-.03^{*}$ \\
\hline NSNE & .09 & .05 & .11 & .47 & .09 & .05 & .13 & .49 & .00 & .00 & $.01^{*}$ & $.02^{*}$ \\
\hline $\mathrm{N}$ & 11029 & 5342 & 4267 & 1966 & 6107 & 3265 & 2761 & 1070 & & & & \\
\hline
\end{tabular}

C. Wage Above Median in Year 1 (Lagged Minimum Wage Increases)

\begin{tabular}{lcccccc} 
Yr 2: & Yr 1: & SE & NSE & SE & NSE & \multicolumn{2}{c}{ SE } & NSE \\
SNE & .26 & .08 & .21 & .10 & $-.04^{*}$ & .01 \\
SE & .40 & .09 & .42 & .07 & .02 & -.02 \\
NSE & .29 & .73 & .31 & .70 & .01 & $-.04^{*}$ \\
NSNE & .05 & .09 & .05 & .13 & .00 & $.04^{* *}$ \\
N & 592 & 754 & 394 & 530 &
\end{tabular}

D. Wage At or Below Median in Year 1 (Lagged Minimum Wage Increases)

\begin{tabular}{|c|c|c|c|c|c|c|c|}
\hline Yr 2: & Yr 1: & $\mathrm{SE}$ & NSE & $\mathrm{SE}$ & NSE & SE & NSE \\
\hline SNE & & .26 & .16 & .26 & .17 & .00 & .01 \\
\hline SE & & .44 & .16 & .42 & .15 & -.03 & -.01 \\
\hline NSE & & .26 & .58 & .27 & .51 & .02 & $-.07^{* *}$ \\
\hline NSNE & & .04 & .10 & .05 & .17 & .01 & $.07^{* *}$ \\
\hline $\mathbf{N}$ & & 745 & 428 & 717 & 393 & & \\
\hline
\end{tabular}

E. Wage in Year 1 Above Year 2 Minimum Wage (Current Minimum Wage Increases)

\begin{tabular}{|c|c|c|c|c|c|c|c|}
\hline Yr 2: & Yr 1: & SE & NSE & SE & NSE & SE & NSE \\
\hline SNE & & .25 & .09 & .23 & .08 & -.02 & -.01 \\
\hline SE & & .39 & .09 & .46 & .09 & $.07^{* *}$ & -.01 \\
\hline NSE & & .30 & .71 & .27 & .73 & -.03 & .02 \\
\hline NSNE & & .05 & .11 & .04 & .11 & -.02 & .00 \\
\hline $\mathbf{N}$ & & 655 & 804 & 265 & 444 & & \\
\hline
\end{tabular}

F. Wage in Year 1 At or Below Year 2 Minimum Wage (Current Minimum Wage Increases)

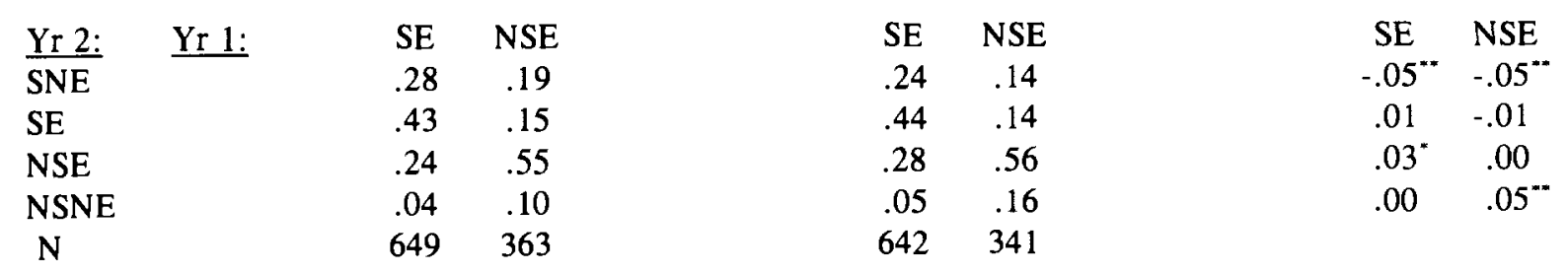


Table 1 (continued)

SNE denotes in school/not employed. SE denotes in school/employed. NSE denotes employed/not in school. NSNE denotes not in school/not employed. In this table, observations with minimum wage increases less than $\$ .10$ were discarded. Many of the small increases came from Washington, D.C., for which the minimum wage is an employmentweighted average of minimum wages for different occupations. In Panels $\mathrm{C}-\mathrm{F}$ wages are required, so only observations from the outgoing rotation groups are used. Differences significant at the ten-percent level are indicated with a ' ${ }^{\prime}$, and those significant at the five-percent level are indicated with a '**'. 
Table 2

Average Hours and Hours Changes

Year 1:

Hours in Year 1

Year 2:

SNE

SE

NSE

SNE SE NSE NSNE

Hours in Year 2 SNE SE NSE NSNE

Difference (Year 2 - Year 1)

$\begin{array}{llll}0.0 & 15.0 & 23.7 & 0.0\end{array}$

$\begin{array}{llll}0.0 & 0.0 & 0.0 & 0.0\end{array}$

$\begin{array}{llll}15.8 & 17.6 & 19.3 & 20.0\end{array}$

$\begin{array}{llll}29.3 & 30.8 & 35.2 & 33.4\end{array}$

SNE SE NSE NSNE

NSNE

$\begin{array}{lllll}0.0 & 19.0 & 32.9 & 0.0\end{array}$

$\begin{array}{llll}0.0 & 16.7 & 30.9 & 0.0\end{array}$

$\begin{array}{llll}0.0 & 0.0 & 0.0 & 0.0\end{array}$

$\begin{array}{llll}0.0 & -15.0 & -23.7 & 0.0\end{array}$

$\begin{array}{llll}15.8 & 1.3 & -2.1 & 20.0\end{array}$

$\begin{array}{llll}29.3 & 11.8 & 2.3 & 33.4\end{array}$

$\begin{array}{lllll}0.0 & -16.7 & -30.9 & 0.0\end{array}$ 
Table 3

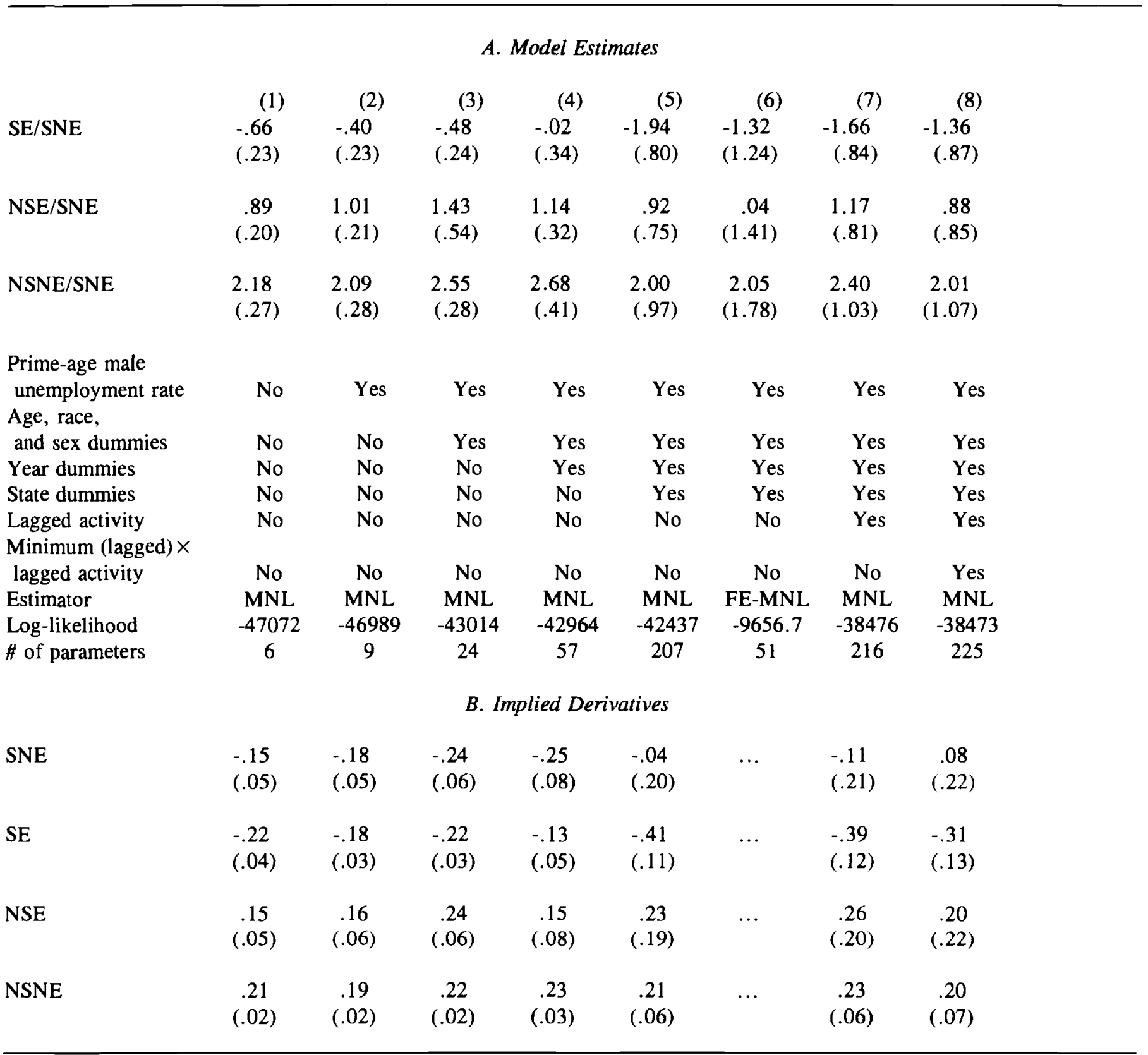

Relative minimum wage variable is not adjusted for coverage. Lagged minimum wage variable is used in all specifications. In column (8), minimum wage effects are defined for the omitted lagged activity (SNE). 
Table 4

Multinomial Logit Estimates of Minimum Wage Effects on Probabilities of School/Work Activities, Alternative Specifications

Implied Derivatives

\begin{tabular}{|c|c|c|c|c|}
\hline & \multirow{3}{*}{$\begin{array}{c}\begin{array}{c}\text { Coverage-adjusted } \\
\text { Rel. Minimum Wage }\end{array} \\
\text { (1) }\end{array}$} & \multirow{3}{*}{$\begin{array}{c}\begin{array}{c}\text { Current } \\
\text { Rel. Minimum Wage }\end{array} \\
(2)\end{array}$} & \multicolumn{2}{|c|}{ Rel. Minimum Wage } \\
\hline & & & Current & Lagged \\
\hline & & & (3) & $\left(3^{\prime}\right)$ \\
\hline SNE & -.16 & -.19 & -.17 & -.04 \\
\hline & $(.24)$ & $(.20)$ & $(.23)$ & $(.22)$ \\
\hline SE & -.35 & -.23 & -.09 & -.35 \\
\hline & $(.14)$ & $(.12)$ & $(.13)$ & (.13) \\
\hline NSE & .29 & .23 & .15 & .20 \\
\hline & $(.24)$ & $(.20)$ & $(.22)$ & $(.22)$ \\
\hline NSNE & .22 & .18 & .11 & .19 \\
\hline & $(.08)$ & $(.06)$ & $(.07)$ & $(.07)$ \\
\hline Log-likelihood & -38478 & -38479 & & \\
\hline \# of parameters & 216 & 216 & & \\
\hline
\end{tabular}

Specifications correspond to those in column (7) of Table 3. See notes to Table 3 for details. Columns (3) and (3') come from a single model including the current and lagged relative minimum wage variable. 
Table 5

Descriptive Statistics and Model Estimates

for Matched and Unmatched Samples

\begin{tabular}{|c|c|c|}
\hline & \multicolumn{2}{|c|}{ Sample Means } \\
\hline & $\frac{\text { Matched }}{\text { (1) }}$ & $\frac{\text { Non-matched }}{(2)}$ \\
\hline SNE & .43 & .36 \\
\hline SE & .22 & .15 \\
\hline NSE & .25 & .33 \\
\hline NSNE & .10 & .17 \\
\hline \multirow[t]{3}{*}{$\mathrm{N}$} & 72,042 & 67,286 \\
\hline & \multicolumn{2}{|c|}{$\begin{array}{c}\text { Marginal effects of } \\
\text { minimum wage from } \\
\text { multinomial logit models }\end{array}$} \\
\hline & Matched & Non-matched \\
\hline SNE & $\begin{array}{l}.11 \\
(.14)\end{array}$ & $\begin{array}{l}-.26 \\
(.14)\end{array}$ \\
\hline SE & $\begin{array}{l}-.30 \\
(.09)\end{array}$ & $\begin{array}{l}-.16 \\
(.06)\end{array}$ \\
\hline NSE & $\begin{array}{l}.06 \\
(.12)\end{array}$ & $\begin{array}{l}.22 \\
(.12)\end{array}$ \\
\hline NSNE & $\begin{array}{l}.13 \\
(.04)\end{array}$ & $\begin{array}{l}.21 \\
(.07)\end{array}$ \\
\hline
\end{tabular}

The data include year 1 and year 2 observations on matched individuals, and all observations on non-matched individuals. The multinomial logit specification is the same as in column (5) of Table 3. 
Table 6

Minimum Wage Effects on Transition Probabilities

A. Based on Multinomial Logit Estimates in Column (7), Table 3

\begin{tabular}{|c|c|c|c|c|}
\hline Year 1: & $\begin{array}{l}\text { SNE } \\
(1)\end{array}$ & $\begin{array}{l}\text { SE } \\
(2)\end{array}$ & $\begin{array}{l}\text { NSE } \\
(3)\end{array}$ & $\begin{array}{c}\text { NSNE } \\
(4)\end{array}$ \\
\hline \multicolumn{5}{|l|}{ Year 2: } \\
\hline$\overline{S N E}$ & $\begin{array}{l}-.09 \\
(.20)\end{array}$ & $\begin{array}{c}.05 \\
(.18)\end{array}$ & $\begin{array}{l}-.12 \\
(.13)\end{array}$ & $\begin{array}{l}-.28 \\
(.14)\end{array}$ \\
\hline $\mathrm{SE}$ & $\begin{array}{l}-.29 \\
(.10)\end{array}$ & $\begin{array}{l}-.56 \\
(.18)\end{array}$ & $\begin{array}{l}-.33 \\
(.10)\end{array}$ & $\begin{array}{l}-.19 \\
(.05)\end{array}$ \\
\hline NSE & $\begin{array}{c}.17 \\
(.14)\end{array}$ & $\begin{array}{c}.39 \\
(.20)\end{array}$ & $\begin{array}{c}.25 \\
(.23)\end{array}$ & $\begin{array}{l}-.02 \\
(.20)\end{array}$ \\
\hline NSNE & $\begin{array}{c}.21 \\
(.06)\end{array}$ & $\begin{array}{l}.13 \\
(.03)\end{array}$ & $\begin{array}{c}.19 \\
(.08)\end{array}$ & $\begin{array}{c}.49 \\
(.18)\end{array}$ \\
\hline$N$ & 17233 & 8658 & 7079 & 3051 \\
\hline \multicolumn{5}{|c|}{ B. Based on Multinomial Logit Estimates in Column (8), Table 3} \\
\hline $\begin{array}{l}\text { Year 1: } \\
\text { Year 2: }\end{array}$ & SNE & SE & NSE & NSNE \\
\hline SNE & $\begin{array}{l}-.07 \\
(.21)\end{array}$ & $\begin{array}{l}.10 \\
(.19)\end{array}$ & $\begin{array}{l}-.10 \\
(.17)\end{array}$ & $\begin{array}{l}-.35 \\
(.29)\end{array}$ \\
\hline SE & $\begin{array}{l}-.23 \\
(.11)\end{array}$ & $\begin{array}{l}-.65 \\
(.29)\end{array}$ & $\begin{array}{l}-.42 \\
(.23)\end{array}$ & $\begin{array}{l}-.46 \\
(.25)\end{array}$ \\
\hline NSE & $\begin{array}{c}.13 \\
(.15)\end{array}$ & $\begin{array}{c}.43 \\
(.26)\end{array}$ & $\begin{array}{c}.32 \\
(.31)\end{array}$ & $\begin{array}{c}.13 \\
(.23)\end{array}$ \\
\hline NSNE & $\begin{array}{c}.17 \\
(.06)\end{array}$ & $\begin{array}{l}.12 \\
(.04)\end{array}$ & $\begin{array}{c}.20 \\
(.08)\end{array}$ & $\begin{array}{c}.68 \\
(.22)\end{array}$ \\
\hline
\end{tabular}


Table 7

Transitions Out of School By Schooling Level

\section{A. Transitions to NSNE (Proportions of Those in Same Year 1 Activity)}

No Increase in Minimum Wage

Yr 1 activity:

Yr. 1 schooling:

$<12$

$=12$

$>12$

\section{SNE}

$.36 \quad .16$

$.50 \quad .68$

.15
Increase in

Minimum Wage $\geq \$ .10$

SNE

.38

.46

.16
SE

.23

.64

.13

Difference
$\frac{\text { (Increase - No Increase) }}{\text { SNE }}$

.02

$-.04^{*}$

$.07^{* *}$

.02
$-.04$

$-.03$

B. Transitions to NSE or NSNE (Proportions of Those in Same Year 1 Activity)

Yr 1 activity:

Yr. 1 schooling:

$<12$

$=12$

$>12$
No Increase in Minimum Wage

SNE or SE
Increase in

Minimum Wage $\geq \$ .10$

SNE or SE

\author{
Difference \\ (Increase - No Increase) \\ SNE or SE
}

In this table, observations with minimum wage increases less than $\$ .10$ were discarded. Many of the small increases came from Washington, D.C., for which the minimum wage is an employment-weighted average of minimum wages for different occupations. Differences significant at the ten-percent level are indicated with a '*', and those significant at the five-percent level are indicated with a $* *$ '.

$\begin{array}{ll}.34 & .03^{* *} \\ .50 & -.02^{*} \\ .16 & -.01^{*}\end{array}$




\begin{tabular}{|c|c|c|c|c|}
\hline \multicolumn{5}{|c|}{ A. 16-17 Year-Olds } \\
\hline Year 1: & $\begin{array}{l}\text { SNE } \\
\text { (1) }\end{array}$ & $\begin{array}{l}\text { SE } \\
(2)\end{array}$ & $\begin{array}{l}\text { NSE } \\
(3)\end{array}$ & $\begin{array}{c}\text { NSNE } \\
\text { (4) }\end{array}$ \\
\hline \multicolumn{5}{|l|}{ Year 2: } \\
\hline$\overline{S N E}$ & $\begin{array}{l}-.05 \\
(.25)\end{array}$ & $\begin{array}{c}.05 \\
(.23)\end{array}$ & $\begin{array}{l}-.09 \\
(.22)\end{array}$ & $\begin{array}{l}-.33 \\
(.18)\end{array}$ \\
\hline SE & $\begin{array}{l}-.17 \\
(.18)\end{array}$ & $\begin{array}{l}-.30 \\
(.30)\end{array}$ & $\begin{array}{l}-.27 \\
(.23)\end{array}$ & $\begin{array}{l}-.18 \\
(.09)\end{array}$ \\
\hline NSE & $\begin{array}{l}.07 \\
(.16)\end{array}$ & $\begin{array}{c}.16 \\
(.25)\end{array}$ & $\begin{array}{c}.12 \\
(.38)\end{array}$ & $\begin{array}{l}-.13 \\
(.24)\end{array}$ \\
\hline NSNE & $\begin{array}{c}.15 \\
(.05)\end{array}$ & $\begin{array}{c}.08 \\
(.03)\end{array}$ & $\begin{array}{c}.24 \\
(.09)\end{array}$ & $\begin{array}{c}.63 \\
(.24)\end{array}$ \\
\hline \multicolumn{5}{|c|}{ B. 18-19 Year-Olds } \\
\hline$\frac{\text { Year 1: }}{\text { Year 2: }}$ & SNE & SE & NSE & NSNE \\
\hline$\overline{\text { SNE }}$ & $\begin{array}{l}-.09 \\
(.37)\end{array}$ & $\begin{array}{c}.07 \\
(.27)\end{array}$ & $\begin{array}{l}-.08 \\
(.14)\end{array}$ & $\begin{array}{l}-.19 \\
(.20)\end{array}$ \\
\hline SE & $\begin{array}{l}-.46 \\
(.11)\end{array}$ & $\begin{array}{l}-.91 \\
(.21)\end{array}$ & $\begin{array}{l}-.31 \\
(.07)\end{array}$ & $\begin{array}{l}-.21 \\
(.04)\end{array}$ \\
\hline NSE & $\begin{array}{c}.26 \\
(.28)\end{array}$ & $\begin{array}{c}.64 \\
(.32)\end{array}$ & $\begin{array}{c}.23 \\
(.26)\end{array}$ & $\begin{array}{l}-.01 \\
(.30)\end{array}$ \\
\hline NSNE & $\begin{array}{c}.29 \\
(.15)\end{array}$ & $\begin{array}{c}.19 \\
(.08)\end{array}$ & $\begin{array}{c}.16 \\
(.14)\end{array}$ & $\begin{array}{c}.41 \\
(.30)\end{array}$ \\
\hline
\end{tabular}

Estimates are based on the specification in column (7) of Table 3, with the models estimated separately by age group. The sample size is 20,104 in Panel A and 15,917 in Panel B. 
Table 9

Minimum Wage Effects on Transition Probabilities, Disaggregated by Race

\begin{tabular}{|c|c|c|c|c|}
\hline \multicolumn{5}{|c|}{ A. Blacks and Hispanics } \\
\hline Year 1: & $\begin{array}{l}\text { SNE } \\
(1)\end{array}$ & $\begin{array}{l}\text { SE } \\
(2)\end{array}$ & $\begin{array}{l}\text { NSE } \\
(3)\end{array}$ & $\begin{array}{l}\text { NSNE } \\
\text { (4) }\end{array}$ \\
\hline \multicolumn{5}{|l|}{ Year 2: } \\
\hline$\overline{S N E}$ & $\begin{array}{l}-.05 \\
(.53)\end{array}$ & $\begin{array}{l}.40 \\
(.53)\end{array}$ & $\begin{array}{l}.00 \\
(.38)\end{array}$ & $\begin{array}{l}-.31 \\
(.40)\end{array}$ \\
\hline SE & $\begin{array}{l}-.34 \\
(.15)\end{array}$ & $\begin{array}{l}-.96 \\
(.40)\end{array}$ & $\begin{array}{l}-.39 \\
(.15)\end{array}$ & $\begin{array}{l}-.22 \\
(.07)\end{array}$ \\
\hline NSE & $\begin{array}{l}-.05 \\
(.26)\end{array}$ & $\begin{array}{l}.28 \\
(.41)\end{array}$ & $\begin{array}{l}-.12 \\
(.47)\end{array}$ & $\begin{array}{l}-.29 \\
(.28)\end{array}$ \\
\hline NSNE & $\begin{array}{c}.44 \\
(.27)\end{array}$ & $\begin{array}{c}.29 \\
(.11)\end{array}$ & $\begin{array}{c}.51 \\
(.25)\end{array}$ & $\begin{array}{c}.81 \\
(.42)\end{array}$ \\
\hline \multicolumn{5}{|c|}{ B. Non-blacks, non-Hispanics } \\
\hline $\begin{array}{l}\text { Year 1: } \\
\text { Year 2: }\end{array}$ & SNE & SE & NSE & NSNE \\
\hline$\overline{\text { SNE }}$ & $\begin{array}{l}-.13 \\
(.23)\end{array}$ & $\begin{array}{l}-.03 \\
(.19)\end{array}$ & $\begin{array}{l}-.15 \\
(.14)\end{array}$ & $\begin{array}{l}-.26 \\
(.15)\end{array}$ \\
\hline SE & $\begin{array}{l}-.23 \\
(.13)\end{array}$ & $\begin{array}{l}-.47 \\
(.21)\end{array}$ & $\begin{array}{l}-.30 \\
(.12)\end{array}$ & $\begin{array}{l}-.17 \\
(.06)\end{array}$ \\
\hline NSE & $\begin{array}{c}.23 \\
(.17)\end{array}$ & $\begin{array}{c}.42 \\
(.24)\end{array}$ & $\begin{array}{c}.35 \\
(.28)\end{array}$ & $\begin{array}{c}.12 \\
(.25)\end{array}$ \\
\hline NSNE & $\begin{array}{l}.13 \\
(.05)\end{array}$ & $\begin{array}{l}.08 \\
(.03)\end{array}$ & $\begin{array}{l}.10 \\
(.07)\end{array}$ & $\begin{array}{l}.32 \\
(.18)\end{array}$ \\
\hline
\end{tabular}

Estimates are based on the specification in column (7) of Table 3, estimated separately by race. The sample size is 6,711 in Panel A, and 29,310 in Panel B. 
Table 10

Minimum Wage Effects on Transition Probabilities,

Based on Initial Wage Relative to Minimum Wage

Year 1:

Final Activity

SNE$$
\text { SE }
$$

(1)

NSE

(2)

\section{Below New Minimum}

SE

(3)
NSE

(4) $\frac{\text { At or Above New Minimum }}{\text { SE }}$

(5)
(6)

\begin{tabular}{|c|c|c|c|c|c|c|}
\hline SNE & $\begin{array}{l}-.06 \\
(.17)\end{array}$ & $\begin{array}{l}-.15 \\
(.13)\end{array}$ & $\begin{array}{l}-.67 \\
(.57)\end{array}$ & $\begin{array}{l}-.38 \\
(.47)\end{array}$ & $\begin{array}{l}-.81 \\
(.47)\end{array}$ & $\begin{array}{l}-.51 \\
(.35)\end{array}$ \\
\hline SE & $\begin{array}{l}-.34 \\
(.18)\end{array}$ & $\begin{array}{l}-.22 \\
(.10)\end{array}$ & $\begin{array}{c}.58 \\
(.57)\end{array}$ & $\begin{array}{c}.18 \\
(.30)\end{array}$ & $\begin{array}{c}.31 \\
(.56)\end{array}$ & $\begin{array}{c}.02 \\
(.29)\end{array}$ \\
\hline NSE & $\begin{array}{c}.30 \\
(.20)\end{array}$ & $\begin{array}{c}.21 \\
(.23)\end{array}$ & $\begin{array}{l}-.13 \\
(.77)\end{array}$ & $\begin{array}{l}-.29 \\
(.86)\end{array}$ & $\begin{array}{c}.44 \\
(.76)\end{array}$ & $\begin{array}{c}.43 \\
(.76)\end{array}$ \\
\hline NSNE & $\begin{array}{c}.10 \\
(.03)\end{array}$ & $\begin{array}{c}.15 \\
(.08)\end{array}$ & $\begin{array}{c}.22 \\
(.11)\end{array}$ & $\begin{array}{c}.50 \\
(.30)\end{array}$ & $\begin{array}{c}.06 \\
(.10)\end{array}$ & $\begin{array}{c}.07 \\
(.27)\end{array}$ \\
\hline $\mathrm{N}$ & 8658 & 7079 & 927 & 475 & 1292 & 1487 \\
\hline
\end{tabular}

Estimates are based on the specification in column (7) of Table 3, except that the contemporaneous minimum wage variable is substituted for the lagged variable. The model also includes an added interaction between the lagged minimum wage and a set of dummy variables describing the respondent's wage in period t-1 relative to the nominal minimum wage in period $\mathrm{t}$; this set of dummy variables is also included. 
Table 11

Minimum Wage Effects on Transition Probabilities, Based on Initial Wage, with Finer Classification of Initial Wage

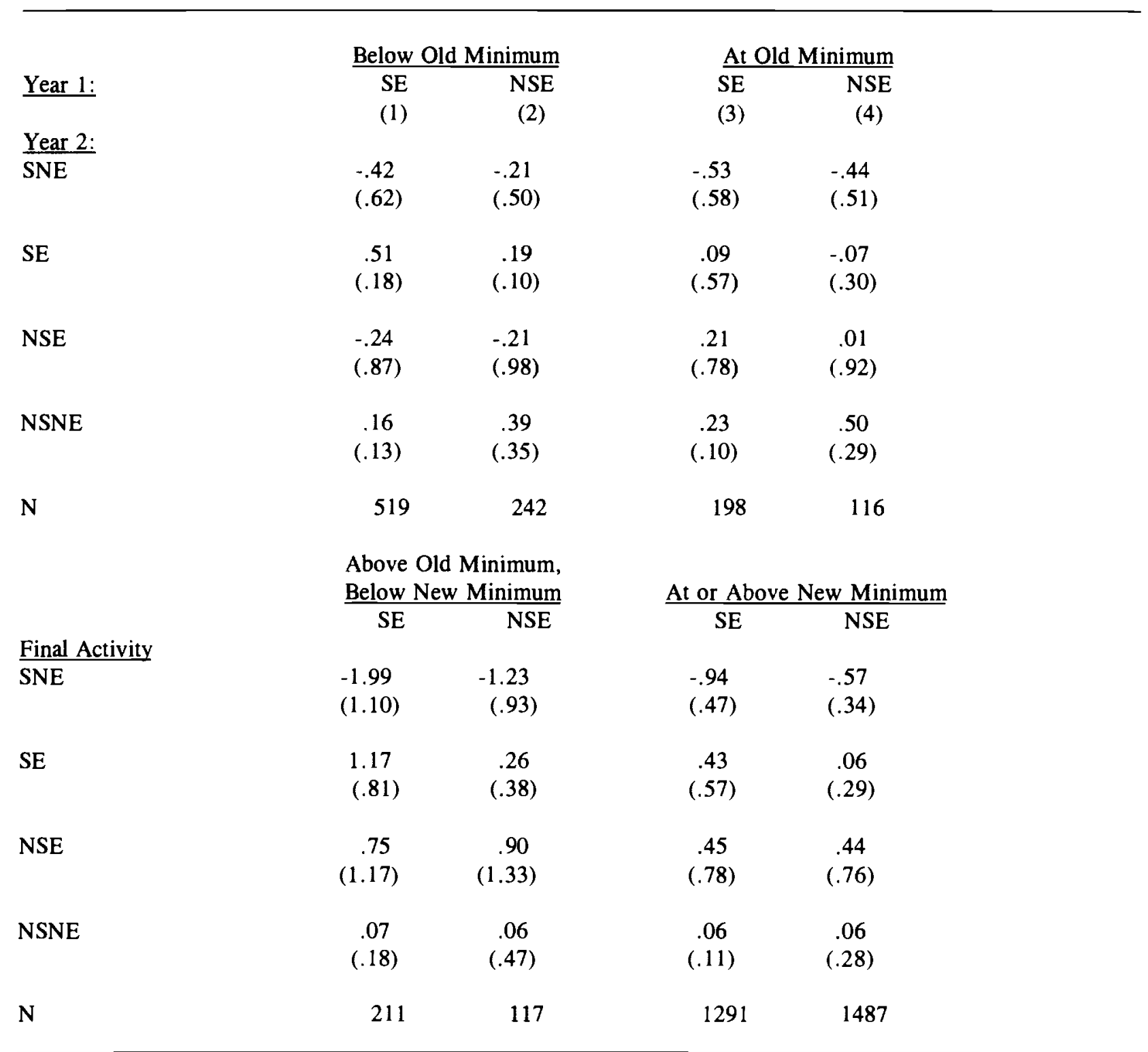

Estimates are based on the specification in column (7) of Table 3, except that the contemporaneous minimum wage variable is substituted for the lagged variable. The model also includes an added interaction between the lagged minimum wage and a set of dummy variables describing the respondent's wage in period t-1 relative to the nominal minimum wage in period $t$; this set of dummy variables is also included. 